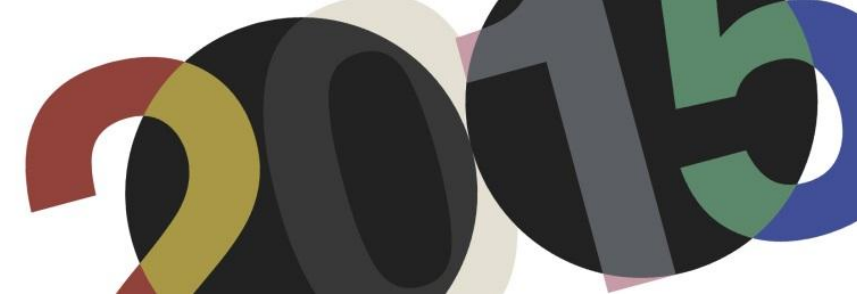

DOI: http://dx.doi.org/10.4995/LC2015.2015.639

\title{
Chandigarh antes de Chandigarh (Cartografía de una idea)
}

\author{
JdelC. Palacios Aguilar \\ Universidad de Lima
}

\begin{abstract}
Resumen: La intención es exponer las ideas que llevaron a Le Corbusier a construir su último y único proyecto urbanístico "Chandigarh"; realizar su sueño de construir sobre una ciudad constituida por aquellos elementos prefigurados desde sus libretas, fotografías y textos de sus Viajes a Oriente, 1911 y Sud América, 1929. Le Corbusier encuentra en Chandigarh su ciudad imaginada, aquella configurada en base al constructo de la razón; montañas, paisajes, árboles, cielos, lagos y ríos, etc. y para ello diseñó un mapa en tres dimensiones que contuviese esa razón fundamental de todos sus años de trabajo: "El monumento de la mano abierta" es un lugar donde superpone esa geografía construida (la idealizada con la hallada), diversos dibujos han ido otorgándole en el tiempo esa capacidad de expresar la vocación del tiempo construido . La mano además de serlo- ya no es más un símbolo o un "signo", es un mapa topográfico que contiene sus propósitos esenciales. Chandigarh se construye sobre esa "ciudad imaginada" - siendo sus numerosos dibujos de montañas, ríos y lagos cartografiados desde los botes, trenes, y aviones, - Le Corbusier siempre estuvo a esperaba encontrar un lugar que coincidiera y encajara con todas esas condiciones naturales-alegrías esenciales- y ese lugar fue Punjab (India); alli es cuando se eclipsan realmente por primera vez todos sus elementos configurados. Las montañas del Himalaya y el Lago Suknha más que elementos geográficos - que constituyen los límites del proyecto- son esencialmente imprescindibles para comprenderlo. El monumento de la mano abierta se configura como un recurso ideográfico en la obra de Le Corbusier.
\end{abstract}

\begin{abstract}
The intention is to present the ideas that led to Le Corbusier to build its latest and unique urban project "Chandigarh", realize his dream of building on a city made up of those elements foreshadowed from his notebooks, photographs and texts of his trips to East 1911 South America 1929. Le Corbusier in Chandigarh discovers his imagined city, that set based on the construct of reason; mountains, landscapes, trees, skies, lakes and rivers, etc. and for this he designed a three-dimensional map that contained the fundamental reason for all his years of work: "The monument open hand" is a place where overlaps that built geography (the idealized with found), various drawings have been giving at the time that ability to express the vocation of time built. Besides hand the be-is no longer a symbol or a "sign" is a topographic map containing the essential purposes. Chandigarh is built on the "imagined city" - remains his numerous drawings of mountains, rivers and lakes mapped from boats, trains, and planes - Le Corbusier was always expected to find a place to coincide and fit with all those naturales- conditions essential- there was joy and Punjab (India); that's when all set items are really overshadow first. Himalaya Mountains and Lake Suknha than geographic features - which form the boundaries of the project are essentially necessary to understand it. The open hand monument is configured as an ideographic resource in the work of Le Corbusier.
\end{abstract}

Palabras clave: constructo, dibujos, viajes, publicaciones, mano abierta. Keywords: Construct, Drawings, Travels, Publications, Open Hand.

\section{Introducción}

Este texto forma parte de una investigación inicié hace unos meses atrás y quizás el mayor motivo para mi es comprender de mejor manera las circunstancias que han ido elaborando la obra de Le Corbusier.

Nos interesa el paisaje construido (dibujado en el tiempo); no el paisaje físico que observamos sino ese paisaje elaborado desde su experiencia; aquel basado en el constructo de su pensamiento. La idea es exponer los criterios y elementos que pudiesen ayudar a comprender la idea de Chandigarh. Hemos seleccionado algunos 
datos, croquis y fotografías que por el propio interés de ésta investigación nos conducen hacia la construcción de la idea que encierra el proyecto de Chandigarh.

En estos últimos años he estado en contacto con la obra del Maestro y recuerdo tres situaciones fundamentales; la primera fue la vista a la exposición "Rethinking Le Corbusier" en Lisboa, Portugal (2008), la segunda, el viaje a una parte de Estambul (Turkia,2015), Rajasthan (India, 2015), y la tercera quizás la más fundamental fue visitar Chandigarh / Ahmedabad (India, 2015); porque puede visitarlas luego de haber estado casi un mes visitando templos y palacios, y fue así que comprendí las resonancias de su obra.

En la visita a la Exposición "Rethinking Le Corbusier”, descubro un libro -entre otros- que contenía Le Corbusier en su biblioteca personal titulado "Construcción de Ciudades Según principios Artísticos" (Camile Sitte) pude obtenerlo años después. Inevitablemente no pasan desapercibidos dos fragmentos que desde el inicio de la lectura -tanto en el prólogo como en la introducción - le dan un sentido aleccionador al joven Le Corbusier, y que a continuación cito: "Conforme a esta intención, el presente libro no intenta ser, ni una historia del urbanismo, ni un escrito de controversia, sino tan solo ofrecer al técnico material de juicio y derivaciones teóricas; quiere contribuir a la enseñanza estética práctica, aumentando el acervo de experiencias y normas del urbanista, a las que se ciñe en la concepción de sus planos parcelarios ${ }^{1}$." Quizás ese "material de juicio" sea comprender el universo del que están constituidas las ciudades, y aquellas "normas del urbanista" sean esa fragua que en el tiempo la visión de la experiencia funda. Le Corbusier procuraba en sus proyectos y teorías urbanas continuar con esa unidad ideológica basada en un urbanismo de confluencias naturales, demás esta citar sus planes y proyectos urbanos, pero es importante ahora mirar hacia atrás y comprender como pudo influir este libro en su pensamiento.

Es importante también destacar la influencia que tuvo del escritor, pintor, crítico de arte y de música el suizo William Ritter (1867-1955). ${ }^{2}$, pero la lección de Sitte parece guiarlo también; "Gratos recuerdos de viaje integran nuestros más bellos sueños. Hermosas imágenes de ciudades, monumentos, plazas, panoramas, pasan ante nuestra alma, y otra vez gozamos de aquello a cuyo lado fuimos tan felices al detenernos. ¡Detenernos! ¡Cuán a menudo podríamos, en esta o aquella plaza, de cuyas bellezas jamás uno se sacia, y sin duda entonces

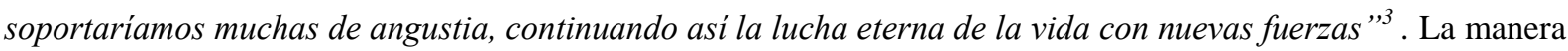
de Le Corbusier de recorrer los territorios y documentarlo no solo gráficamente nos han dejado carnets llenos de experiencias.

Los dibujos de Le Corbusier a mi entender viven tres momentos; el momento en el que dibuja y anota, el momento en el que contiene lo dibujado, y el momento en el que el dibujo transmuta en el tiempo generando un nuevo dibujo (capacidad de observación / constructo). Pero no solo son dibujos, dibuja y fotografía lo que ve, luego proyecta lo que ha aprendido y dibujado, y luego fotografía lo que ha construido; vive un proceso creativo cíclico permanente, algunos dibujos de sus carnets aparecen en sus diseños posteriormente como si estuvieran

\footnotetext{
${ }^{1}$ Sitte, C. La Construcción de Ciudades según principios artísticos. Barcelona, 1929.

${ }^{2}$ Ritter había sido un gran viajero, buen conocedor de la Europa central y su cultura, de la que era un apasionado admirador, por lo que Jeanneret le oiría con frecuencia hablar de los paisajes de Bohemia, de la cultura popular de los Balcanes, o de las bellezas de Constantinopla, despertando y alentando en él un gran deseo de conocer aquellas tierras. [...] Le Corbusier siempre agradecerá la influencia que William Ritter tuvo en su formación en aquel decisivo año de 1911. Dejará constancia de ello en la introducción al primer volumen de su Obra Completa (1930), en la que se referirá a Ritter como el mentor y amigo a quien pudo confiar sus dudas e incredulidades, aquel que le ayudó a encontrarse a sí mismo y a descubrir que en esta vida uno sólo puede contar con sus propias fuerzas. [...] MONTES, C. En el Centenario del Viaje a Oriente. Fotografías, cartas y dibujos. Valladolid, 2011

${ }^{3}$ Sitte, C. La Construcción de Ciudades según principios artísticos, p. 1
} 
emplantillados en su memoria y reproducidos en trazos -casi mecánicamente- por sus manos. Es desde los dibujos de los lugares - y con los alcances de sus pensamientos y escritos- que intentaremos el proyecto de Chandigarh.
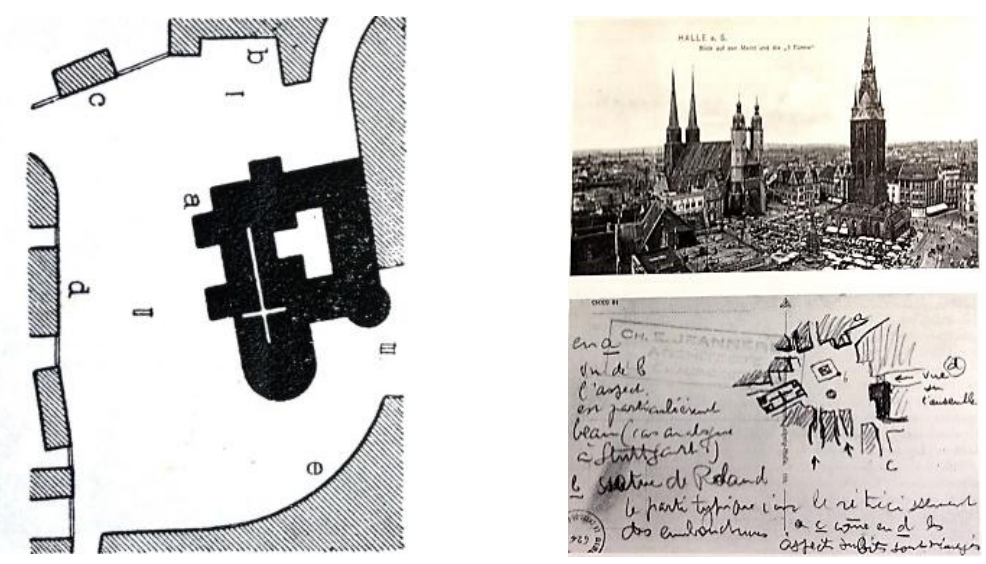

1. Camille Citte "Construcción de Ciudades según principios artísticos" Plaza de la Catedral en Munster. p. 894

2. Postal enviada por Le Corbusier a sus padres_Halles jun 19105

La segunda circunstancia fue la visita a la ciudad de Estambul, ruta hacia Rajasthan (Udaipur, Jodhpur, Jaipur) allí encontré referencias de un Le Corbusier atento que registró todo cuanto vio, como demuestran sus carnets. ${ }^{6}$ En las visitas realizadas a los distintos lugares y templos comprendí las disposiciones de las plazas, espacios entre los edificios, los ingresos a los fuertes y palacios y las alturas que se gozaba desde sus terrazas, luego al visitar Chandigarh pude vivir cercanamente la misma experiencia sensorial.

La tercera circunstancia se ha revelado al visitar y recorrer la ciudad de Chandigarh. Allí se decantan muchas de sus exploraciones teorizadas y explicadas en varias de sus publicaciones; El viaje a Oriente, Hacia una arquitectura, Por las Cuatro Rutas, Cuando las Catedrales eran Blancas, Precisiones, La Ciudad del Futuro, Aircraft, El Poema del Angulo recto, La Pequeña Casa, El Modulor, Mise au Point); intentaremos buscar resonancias que nos permitan clasificar aquellos momentos que han constituido aquella ciudad que tenía pensada.

Es importante mencionar que en el desarrollo del proyecto de Chandigarh (1951-1965) ha habido un elemento que requería insistentemente ser edificado; nos referimos al monumento de la Mano Abierta. El tiempo testigo de sus búsquedas nos permiten ver las posibilidades de ese modelo topográfico desde donde se va construyendo el proyecto que más cercano ha estado de su pensamiento.

\footnotetext{
${ }^{4}$ En el libro de Sitte: "La Construcción de Ciudades según principios artísticos" (1889), está enteramente dedicado al estudio de las ciudades, a la relación entre los edificios, monumentos y plazas, a la disposición y formas de las plazas, estudios sobre la irregularidad, agrupación y disposición de las plazas; y también en el apéndice incluye el empleo de la vegetación en las grandes ciudades. Es un libro lleno de gráficos y análisis desde donde SITTE aborda una conclusión generalista en donde considera que las obras de arte no pueden crearse por comisiones, ni oficinas, sino individualmente, y un plano de ciudad, por debe producir un efecto artístico, es una de tantas. Incluso declara a Constantinopla como un modelo perfecto de ciudad que debemos de imitar; luego comprendemos de qué manera influirá en la visita que Le Corbusier hace en su viaje a Oriente en 1911.

${ }^{5}$ Brooks, A. Le Corbusier's formative years, Charles- Edouard Jeanneret At la Chaux-des-Fonts, Chicago, 1997

${ }^{6}$ El viaje a Oriente que emprendió Charles-Édouard Jeanneret, entre los veintitrés y veinticuatro años, en compañía de su amigo Auguste Klipstein. En un recorrido que comienza el 23 de mayo y termina el 1 noviembre de 1911, el viaje transcurre por la región de Bohemia, (actual Checoslovaquia, creada 1918), Austria, Hungría, Serbia, Rumania, Bulgaria, Turquía, Grecia e Italia. Daza, R. Tras el Viaje de Oriente. Barcelona,2015
} 
Estas aproximaciones aún no contienen la totalidad de las búsquedas, es solo un camino y una pausa sugerente de esta investigación,; el hilo generador de este acercamiento y la documentación hallada me parece que aportan considerablemente a comprender mejor la idea que se propone, idea que está sensiblemente explicada en su último libro, en el mise au point ${ }^{7}$.

La idea de analizar la construcción de una idea sobre Chandigarh y con ello la Mano abierta es para intentar restablecer sus pensamientos formulados y que procuró construir esa evidencia para que no quedara en formulaciones teóricas. La mano abierta representa un pensamiento, no la comprendemos como un signo, sino como una cartografía de su pensamiento, por ello. decodificar esa pieza es de alguna manera codificar nuevamente la obra de Le Corbusier, comprender como se ha ido constituyendo y consolidando un mismo proyecto de arquitectura que comenzó en su viaje a Oriente (1911).

Pero, las preguntas me aparecen al regreso del viaje; ¿Porque son importantes todos los elementos que construyen ese territorio para Le Corbusier?, ¿Porque se repiten los paisajes construidos y dibujados a lo largo de su obra? ¿Cómo es el paisaje que encuentra en Chandigarh, diseña un lugar? o construye sobre él? ¿Porque es importante en la configuración del proyecto el Lago artificial Sukhna? ¿Porque es importante la cordillera Himalaya? ¿Porque la mano abierta debería de ser construida en ese lugar e insistir en ello hasta el final de sus esfuerzos? ¿Es la mano abierta realmente la síntesis de su obra? ¿Es la mano abierta el código de su pensamiento construido por elementos esenciales para la vida del hombre? ¿Representa -la mano abierta- una topografía hecha a partir de una imagen evolucionada de su pensamiento? ¿Contiene el monumento esas "alegrías esenciales" (montañas, caminos, horizontes y lagos) de las que nos hablaba Le Corbusier? ¿Es la mano abierta una cartografía de sus intenciones? ¿Siempre tuvo forma de mano? ¿Es realmente un monumento que refleja toda la síntesis de su obra completa o un signo político?

Intentaremos abordar todas estas interrogantes intercalando los momentos en los que fueron realizados gran parte de sus estudios (dibujos, notas, textos, pensamientos, etc.).

\section{Metodología propuesta para el estudio}

La metodología sitúa en un mismo plano de análisis (por las fechas ${ }^{8}$ en las que se redactó y luego publicó), el Modulor I-II (1950,1955), el Poema del Ángulo Recto (1947-1953) y La Pequeña Casa (1954) como elementos que aparecen durante la gestación de Chandigarh (Punjab, India). La metodología está organizada desde los propios acontecimientos arquitectónicos, algunos en orden cronológico y otros entrelazándose entre sí ayudando a comprender lo que se plantea explicar.

Chandigarh al parecer fue el lugar donde halló todas esas posibles deducciones y contribuciones que dejaría como aporte a la arquitectura no solo desde el Urbanismo sino un lugar donde se desarrolle la vida a favor del hombre.

El segundo factor considerable es la documentación teórica y gráfica reunida en sus viajes; son momentos claves que establecen con el maestro un nexo con la historia y con los lugares que proyectaba; cúmulo de información generada a partir de la observación de sus viaje a Oriente y a Sud América.

\footnotetext{
${ }^{7}$ Torres, J. Pensar la Arquitectura: Mise au point de Le Corbusier. Madrid,2014

${ }^{8}$ Las fechas, datos y toda la documentación que se tiene ha sido consultada directamente de la página web de la fundación Le Corbusier: http://www.fondationlecorbusier.fr
} 
El tercer factor importante es el encargo para el diseño de Chandigarh, donde trabajaron junto a Pierre Jeanneret (primo y encargado del proyecto), Maxwell Fry y Jane Drew ${ }^{9}$. Es fundamental establecer el nexo con su primo Jeanneret ya que anteriormente había colaborado con él - en la que a mi parecer dejaron un ejemplo de urbanismo sintetizado- en los planos de la pequeña casa que se construyó en Suiza, "la pequeña casa fue construida 1923/1924 según los planos de Le Corbusier y de Pierre Jeanneret (N.de.E.) $)^{10}$, luego nos detendremos en ver sobre las implicancias de dicho proyecto y como se hila con la obra de Le Corbusier y Chandigarh.

El cuarto momento está en el pequeño poemario sobre Urbanismo conocido como el Poema del Angulo Recto ${ }^{11}$ que fue elaborado por Le Corbusier entre los años 1948-1955 donde pone de manifiesto las condiciones sobre su trayectoria armónica en la concepción de la arquitectura.
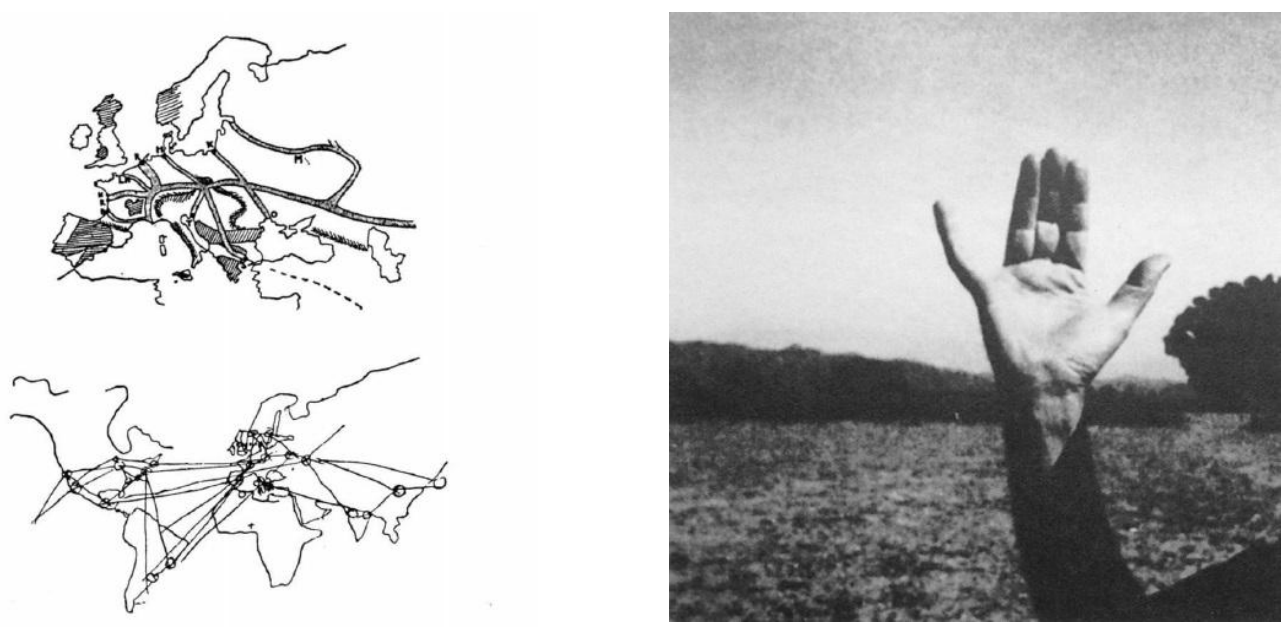

3. Imagen en El Modulor (FLC) p.117, cerrando el capítulo 4 donde se muestra el mapa del viaje a Oriente y seguido el mapa total de todos sus viajes (a Sud América , Europa e India)

4. Le Corbusier's open hand on the Capitol City $1951^{12}$

El quinto propósito lo establece el Monumento de la Mano abierta. Se han escrito innumerables textos y se han querido hallar diversos significados, algunos explicados por el mismo Le Corbusier y sin embargo pensamos que la idea de la mano se ha ido "dibujando" en el tiempo y que finalmente se le ha dado una connotación simbólica, ya que es lo que visualmente evidencia.

\footnotetext{
${ }^{9}$ Huse, M. Le Corbusier, Barcelona, 1986

${ }^{10}$ Le Corbusier. Una Pequeña Casa, Argentina, 2014

${ }^{11}$ AA.VV. Le Corbusier y las Sintesis de las artes; El poema del ángulo recto, Madrid, 2006

${ }^{12}$ Seguin, P. Le Corbusier Pierre Jeanneret (Chandigarh India). Francia, 2014
} 

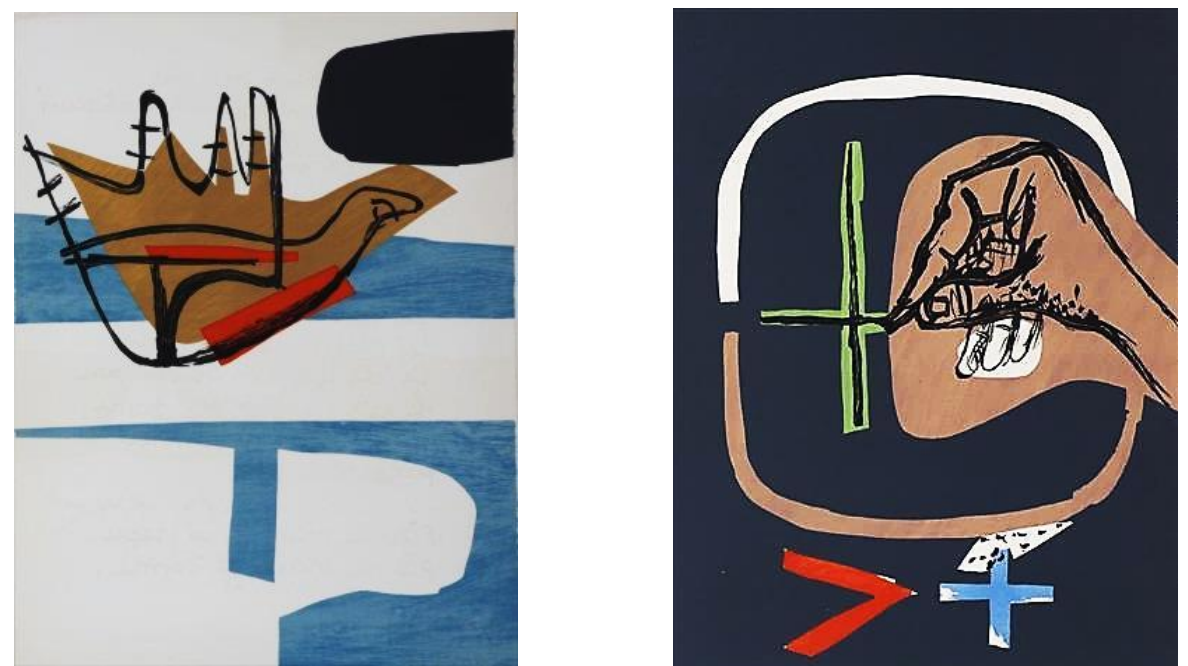

5. El Poema del Angulo Recto p.145_F.L.C Éditions Tériade, Paris, 1955

6. El Poema del Angulo Recto p.151_F.L.C Éditions Tériade, Paris, 1955

La metodología intenta recomponer las ideas que Le Corbusier plantea sobre el diseño de las ciudades que llego a proyectar - solo nos enfocaremos en los proyectos donde hemos encontrado elementos que aparecen coincidentemente en Chandigarh - y que fue componiendo en sus dibujos y escritos, reiterando el entorno hallado, trasponiendo sus condiciones proyectuales y procurando un paisaje-herramienta para el hombre.
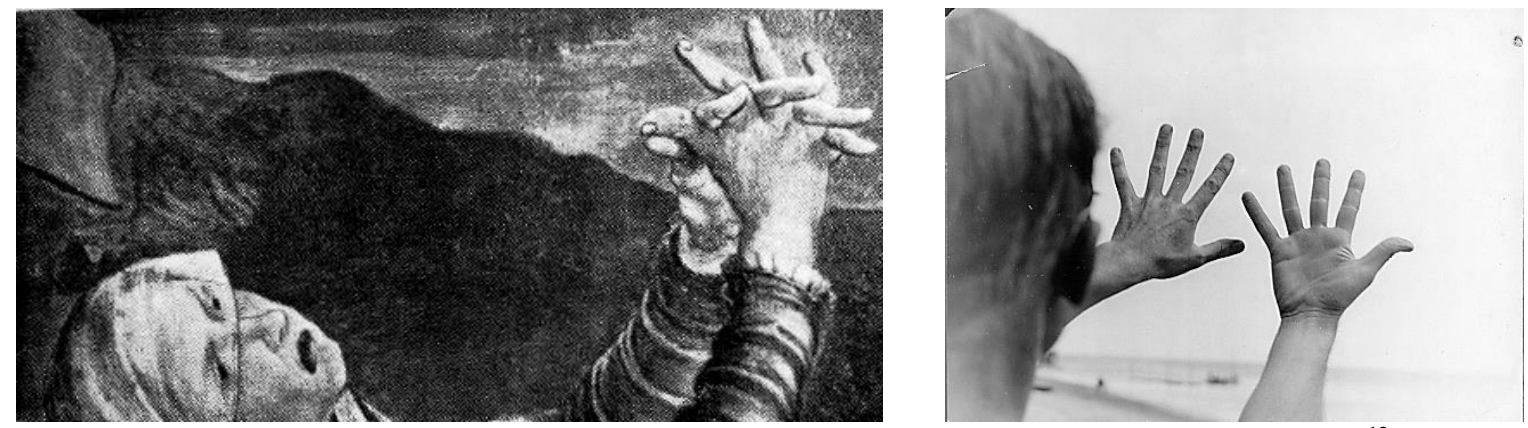

7. Una ilustración de la Maquette établie par Trouin sur l'iconographie Marie-Madeleine , en la Obra Completa ${ }^{\mathbf{1 3}}$ 8. FLC L4.3.27. ${ }^{14}$

Habría que reconfigurar Chandigarh, precisar información sobre su viaje a Oriente, acercarnos a la pequeña casa construida sobre el lago Lemán, atender el manejo de las alegrías esenciales sobre la concepción del urbanismo junto a la regla de las 7 vías y la implicancia directa del Modulor en el estudio de las proporciones.

\section{Resonancias desde el interior}

Esa naturaleza construida que le atrajo tanto -como la que halló al borde del lago Leman (1923) - como el lugar hallado en Chandigarh lo define así: "Estamos en una llanura; la cordillera del Himalaya cierra solemnemente el paisaje por el norte "15 El espacio que concebía como un lugar donde debía desarrollarse una ciudad aparecía nuevamente sobre un fondo montañoso. Quizás le recuerde a los Andes o a los Alpes, pero siempre estaba la idea recurrente "la flor, la planta, el árbol y la montaña se alzan sobre el suelo, viven en un ambiente dado. Si alguna vez llaman la atención por su actitud, verdaderamente firme y soberana, es porque se destacan en su

\footnotetext{
${ }^{13}$ Le Corbusier et Pierre Jeanneret, Euvre complète 1946- 1952 Vol 5 p.27

${ }^{14}$ VV.AA, Le Corbusier, Le Grand, p.458

${ }^{15}$ Le Corbusier. El Modulor/El Modulor 2. Madrid, 2005
} 
presencia, pero provocando resonancias a su alrededor. Nos detenemos, sensibles ante tantos vínculos naturales y contemplamos emocionados por tantas concordancias que orquestan tanto espacio, y consideramos entonces que lo que vemos irradia luz.",16

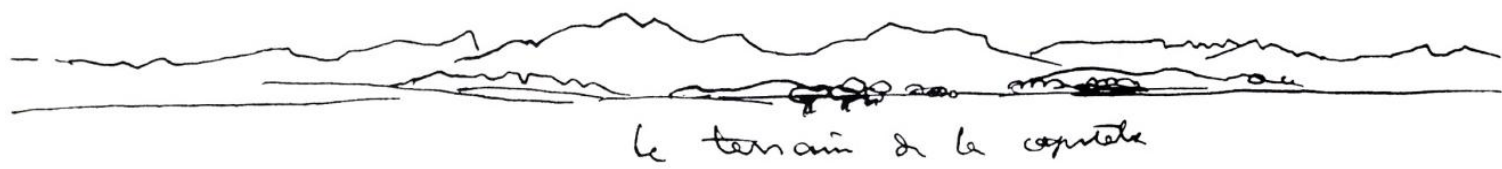

9. Le Terrain de la capitale, $1951^{17}$

En los lugares buscaba esa armonía que encierra un pensamiento y coloca al hombre por encima de lo espiritual. En su libro Como Concebir el Urbanismo (1946) explica esa concepción del lugar; "Existe unidad entre las obras de la naturaleza y las obras del espíritu humano”. Al reconocer la soberanía de la naturaleza, Descartes ha puesto un término a la de la Razón; un término a la primacía del verbo. Lo que cuenta ya no son las palabras sino las realidades" 18 como aguardando ese momento para vaciar su experiencia y voluntad casi siempre son textos que aparecen en la mismas direcciones. En otra de sus publicaciones "La Ciudad del Futuro(1924) aparecen unas condiciones propuestas también desde el paisaje y la vida, que reflejan y mantienen coherentemente esa filosofía planteada en Chandigarh, citando al mismo Le Corbusier ; “ Posiblemente corresponderá al nuevo espíritu arquitectónico, al urbanismo inminente, satisfacer las más remotas funciones humanas, reverdeciendo el paisaje humano y mezclando a nuestra labor la naturaleza" 19 La medida justa entre el hombre y la naturaleza era un motivo fundamental en su arquitectura en éste mismo libro se acerca a las teorías de Sitte y advierte que "La ciudad es un instrumento de trabajo[...]Es la manumisión de la naturaleza por el hombre. Es una acción humana contra la naturaleza, es un organismo humano de protección y trabajo. Es una creación [...]. La poesía es un acto humano: las relaciones concertadas entre imágenes perceptibles" 20 Los elementos debían estar en armonía, el hombre debía de situarse por encima de la naturaleza pero no para dominarla sino para comunicarse con ella y las medidas del hombre "el Modulor" proponían ese encuentro casi nupcial.

En 1937 describe esa relación armoniosa entre el alma del hombre "espíritu” y la naturaleza, las alegría esenciales "Sol. Espacio y árboles; los he comprendido como materiales fundamentales del Urbanismo, portadores de alegrías esenciales al afirmarlo, quiero volver a poner al hombre en sus ciudades, en el corazón mismo de su medio natural, de sus emociones fundamentales" ${ }^{\text {"2l }}$. Siempre por encima de toda arquitectura esta ese propósito de llevar al hombre de situarlo por encima del medio natural-filosófico- pero privarlo de árboles sería destruirlo. Y es que en Chandigarh las montañas que delimitan el paisaje juntos a los espacios verdes -como aquellos vergeles que tanto acuso en Estambul - han configurado esa arquitectura que participa del entorno, lo observa y se reune con él.

\footnotetext{
${ }^{16}$ Ibídem, p225

${ }^{17}$ Seguin, P. Le Corbusier Pierre Jeanneret (Chandigarh India), Francia, 2014

${ }^{18}$ Le Corbusier. Cómo concebir el urbanismo, Argentina 2013

${ }^{19}$ Le Corbusier. La ciudad del Futuro, p.61

${ }^{20}$ Ibidem, p. 15

${ }^{21}$ Le Corbusier, Cuando las Catedrales eran Blancas, Madrid, 2007
} 
El libro "La Pequeña Casa (1923)" se menciona por dos razones ${ }^{22}$; primero porque como mencionamos es un ensayo de menor escala de un urbanismo construido en el espíritu y luego llevado a otra escala, faltaba hallar el lugar. En el caso de Chandigarh el lugar ya estaba, faltaba que Le Corbusier lo mirara para darse cuenta que todo estaba allí, faltaba el Lago Sukhna. Pero volvamos a la Pequeña casa, allí se encuentran realmente todos los motivos antes mencionados, tenemos el Lago Leman, las montañas Neucahtelesas, los árboles, el lugar, el paisaje, la cubierta habitada, el encuadre, los planos que ya estaban hechos, el ángulo recto. Es sabido que la casa fue diseñada para sus padres y que luego se buscó el lugar para edificarla. Es importante mencionar que la "la pequeña casa fue construida en 1923 /1924 según los planos de Le Corbusier y de Pierre Jeanneret.(N.d.E)"23 Ambos participaron juntos en la construcción de la ciudad de Chandigarh, por esa coincidencia es que reanudo nuevamente el carácter de esa participación.

En ese mismo año Le Corbusier publica "Hacia una Arquitectura"( 1923) donde aparece coincidentemente el dibujo de la Acrópolis junto al dibujo del Templo de Minerva; analiza las relaciones entre los elementos que conforman la perspectiva, constantemente son reflejadas en el Modulor y trabajadas en Chandigarh en estudios con palos para hallar las distancia armónica entre los edificios. Es importante ver la relación de la planta del dibujo hecho por Le Corbusier del Forum de Pompeya y el de la Pequeña casa por dos razones: la primera es porque toma la configuración de la casa como si de una pequeña ciudad se tratara pero considerando los elementos naturales del paisaje, sin embargo en Chandigarh solo refiere el paisaje como el espíritu del lugar, tomando la historia como un dispositivo y superponiéndolo al lugar. No es tan evidente cuando han pasado muchos años, pero si es evidente que Le Corbusier tenía en la mano todos los trazos que hizo, por ello hay muchas coincidencias entre sus dibujos y sobre lo que proyectó, incluso coincidencias simultaneas.

Si superponemos ambas plantas vemos que guardan una estrecha relación entre sus medidas y orientaciones, el medio que rodea la arquitectura siempre ha estado como condicionante al abordar sus proyectos, incluso desde antes de que se apareciera el lugar se tuvo el proyecto, y es porque ha estado presente en su subconsciente ya su infancia lo revela.
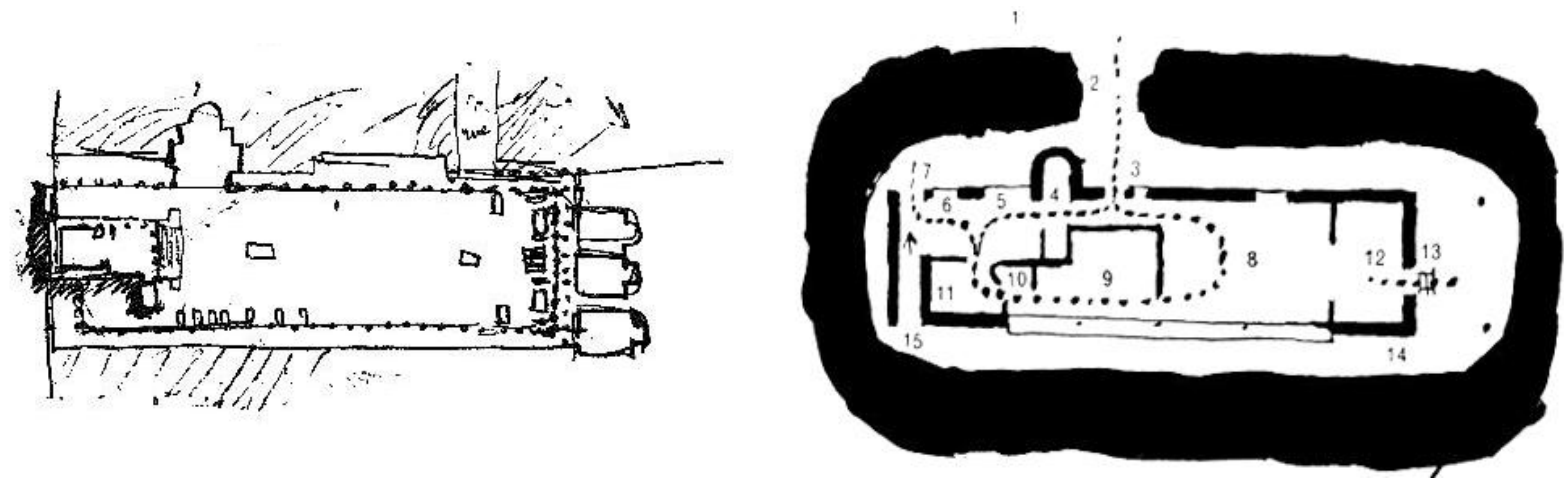

10. Imagen del Foro de Pompeya publicada en "Hacia una Arquitectura", 1927

11. Dibujo de la planta de "La Pequeña Casa", realizada en 1923

La presencia de la naturaleza se hace evidente en La Chaux no solo por sus topografías sino también por el marcado contraste entre el cálido verano y el frío y nevado invierno, debido a su altitud y latitud. De los años transcurridos en La Chaux, Jeanneret (cuyo padre fue presidente del club local de montaña) escribió: “Mi

\footnotetext{
${ }^{22}$ Solo haremos mención a esta casa - por encontrar estrechas relaciones con Chandigarh- porque el libro "la pequeña casa" fue publicado -luego de 21 años de su construcción - en 1954, es relevante que se haya escrito en ese momento, ya que el proyecto de Chandigarh se inicia en 1951.

${ }^{23}$ Le Corbuiser, Una pequeña Casa, p.15
} 
infancia la pase con mis amigos en medio de la naturaleza. Mi padre, además era ferviente devoto de los ríos y las montañas que configuraban nuestro paisaje. Constantemente estábamos entre cimas, siempre en contacto con la inmensidad del horizonte. Cuando la niebla se extendía interminable parecía un verdadero mar, al que nunca había visto. Era el espectáculo supremo. El periodo de la adolescencia fue de curiosidad insaciable, sabía cómo eran las flores, la forma y los colores de los pájaros, comprendía el crecimiento de los árboles y cómo guardaban el equilibrio en medio de una tormenta, en 1925 en L'Art Decoratif d'Aujourd'hui, París ",24

Por estos años iniciales no hay Modulor, pero sí se formaban esas "alegrías esenciales” y relaciones con el paisaje que siempre menciona "Del mismo modo en la Acrópolis de Atenas, espacios y volúmenes dispuestos por la topografía y por una ciencia perfecta, aliados al circo que forman las montañas y frente al mar cubierto de montañas e islas, han convertido este lugar en algo caro para el corazón" 25 y no deja de hacerlo en sus posteriores teorizaciones; en Chandigarh refleja ese mismo espíritu como lo explica Kenneth Frampton "los edificios representativos de los tres poderes-el Tribunal Supremo, la Asamblea y los Ministerios- estaban relacionados no por la configuración del emplazamiento, como en la Acrópolis, sino más bien por líneas abstractas muy lejanas, un escorzo progresivo, cuyos únicos límites parecían estar en las montañas del horizonte" Esas "líneas abstractas "derivan de las medidas del Modulor, de las perspectivas producidas en sus estudios de la Acrópolis y sobre la aplicación de los análisis de movilidad planteados en la conocida "Regla de las 7 vías" y que vio la luz en Chandigarh.

\section{Entre el Himalaya y el lago Sukhna}
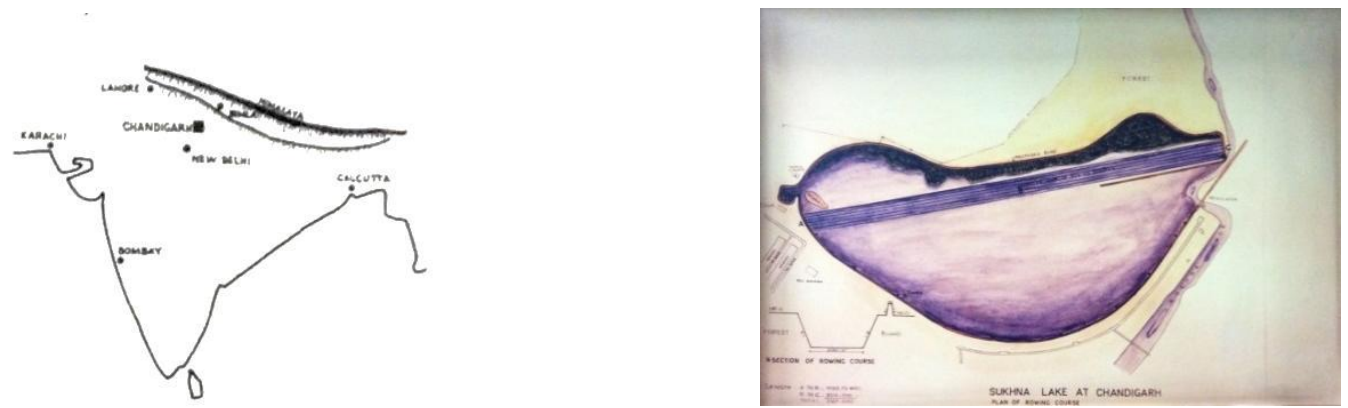

12. Sketch of Chandigarh in the Architect on Buildings News, 6 sep $1951^{26}$

13. Lago Sukhna(1956) ${ }^{27}$

El encargo surge al lograr India su independencia en 1947, con ello la vocación de parte del primer Ministro J. $\mathrm{Nehru}^{28}$ y la de Le Corbusier: "tenía 60 años cuando recibi mi primer y único encargo oficial del Estado, y esto, sin duda! era para reírse un poco! Todo el mundo fue alertado. ; El espíritu, la Edad Media. Después de la Guerra: reconstrucción, para Corbucero"29 . Aquí se refería sobre aquella lejana y ahora cercana posibilidad de elaborar su primer proyecto urbanístico; en otras ocasiones se había truncado por una u otra razón, pero sin

\footnotetext{
${ }^{24}$ Baker, G. Análisis de la forma. Barcelona, 2000

${ }^{25}$ Le Corbusier, Cuando las Catedrales eran Blancas, p. 140

${ }^{26}$ VV.AA, Le Corbusier, Le Grand, p.455

${ }^{27}$ Fotografía realizada por el autor en el Centre Le Corbusier en Chandigarh (India) 22 enero 2015.

28 "Será una ciudad nueva, un símbolo de la libertad de la India. Firme con las tradiciones del pasado [...], expresión de la confianza del país en el futuro" HUSE, N. Le Corbusier, Barcelona, 1986

${ }^{29}$ Torres, p. 14
} 
embargo este proyecto si se llegó a concretar y allí es donde logra aplicar su experiencia de vida. Al paisaje encontrado en Chandigarh -remarcado por ese fantástico borde montañoso del Himalaya-, le aparece el Lago Sukhna que fue creado para delimitar parte del extenso territorio, de esta manera estaba completando el límite que no tenía su plan ideal (imaginado). El proyecto significaba contener de alguna manera los limites pero dotando a la ciudad de un promenade con árboles y agua tal como está en la actualidad (2015). Un lugar de paseo para los locales y extranjeros, un lugar en donde la naturaleza del lugar permite que se practiquen las regatas cada año y donde se prohibió -desde que Le Corbusier lo propuso- las lanchas a motor para evitar la contaminación y preservar lo natural; la parte superior del paseo marítimo están también prohibidas de tráfico rodado, hasta ahora. A tanto llego el nivel de implicancia con el proyecto y con la integra exposición espiritual de cada uno que cuando fallece Jeanneret -a dos años de fallecer Le Corbusier y a uno de fallecer Jawaharlal Nehru- en 1967 hace que sus cenizas fuesen arrojadas sobre el lago Sukhna. ${ }^{30}$.

La orientación de los edificios estaba regida por los vientos predominantes y la orientación solar, así desde el Lago Sukhna se podía observar la ciudad o divisar parte de los edificios asomarse desde el horizonte, como sucede con las Unités y con el Convento de la Tourette. Pero también encontramos en sus archivos las fotografías que tomo en su viaje por Esztergon ${ }^{31}$ desde donde se aprecia la Catedral desde el Danubio, la imagen es tomada desde un lado del barco y el grado de tranquilidad y contemplación es similar al logrado muchos años después en Chandigarh desde el Lago Sukhna. La fotografía de Chandigarh data de 1965 pero no se tiene el autor. Concuerdan ambas cúpulas, la de la del Palacio de la Asamblea destacando sobre el horizonte, donde la pátina del tiempo no ha envejecido el concreto de los edificios como están ahora.
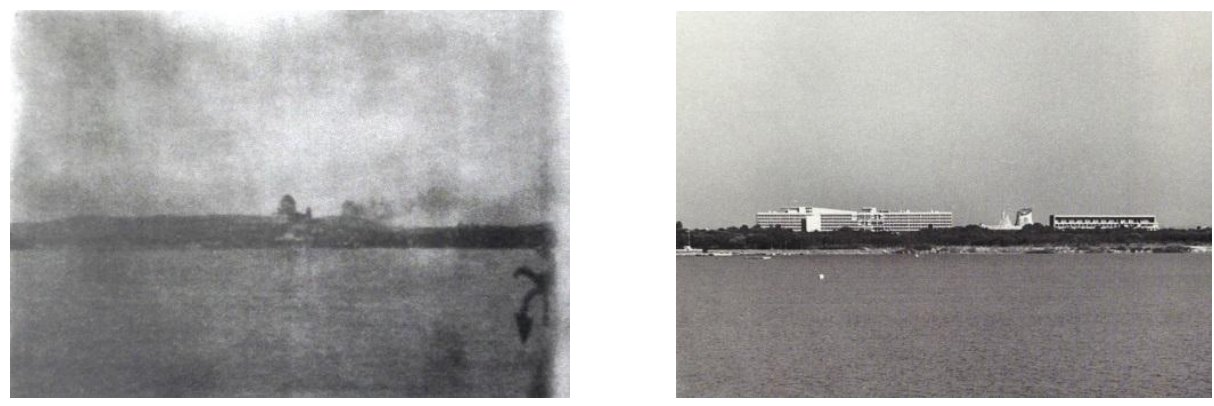

14. Catedral de Esztergon ${ }^{32}$

15. Secretariat, Legislative Assembly and High Court, seen from Sukhna Lake in sector 1,ca.1965 $5^{33}$

En sus crónicas escribe una nota que al leer nos hace anticipar lo que realizó en Chandigarh "Aparece Esztergon, extraña silueta: un cubo y una cúpula sostenida por varias columnas. De lejos todo presagia una maravilla. Cubo en el que late un ritmo admirable y que los montes nacientes presentan como una ofrenda sobre el altar que le dedican. ${ }^{\text {"34 }}$

El lago Sukhna es fundamental para comprender la nueva concepción de la ciudad de Chandigarh, para Le Corbusier este "Boulevard de Auxs"- There is now a lake, a body of water which has transformed the local climatic condition ${ }^{, 35}$. hoy he podido recorrer el borde del lago y la sensación contemplativa y de gozo esencial

\footnotetext{
${ }^{30}$ Seguin, P. p.43

${ }^{31}$ Daza, El viaje a Oriente, $p .42$

${ }^{32}$ Ibídem

${ }^{33}$ Seguin, P. p.72

${ }^{34}$ Daza, El viaje a Oriente, $p .43$

${ }^{35}$ Le Corbusier et Pierre Jeanneret, Euvre complète 1952- 1957. Vol 6 p.53
} 
es sin duda un gran aporte en la vida de los hindúes, sin embargo no se ha encontrado mayor material que pudiera darnos mayores alcances.

\section{Poemario de Urbanismo y el espacio Inefable ${ }^{36}$}

El ángulo recto referida siempre a la incidencia de la vertical sobre la horizontal y que funda de alguna manera su pensamiento urbanístico, tiene que ver con el recorrido del sol, “El ángulo de incidencia no pasará jamás por la pequeña casa. Alcanza (y deslumbra) a los habitantes de las colinas, ;los de la cota cincuenta o cien! La "gente» ignora el ángulo de incidencia" 37 Pero no es sino que a mediados de $1947^{38}$ que inicia el Poema del Ángulo Recto, fue escrito entre los años 1948 y 1955 y abarca parte del periodo en la cual Le Corbusier estaba trabajando en Chandigarh.
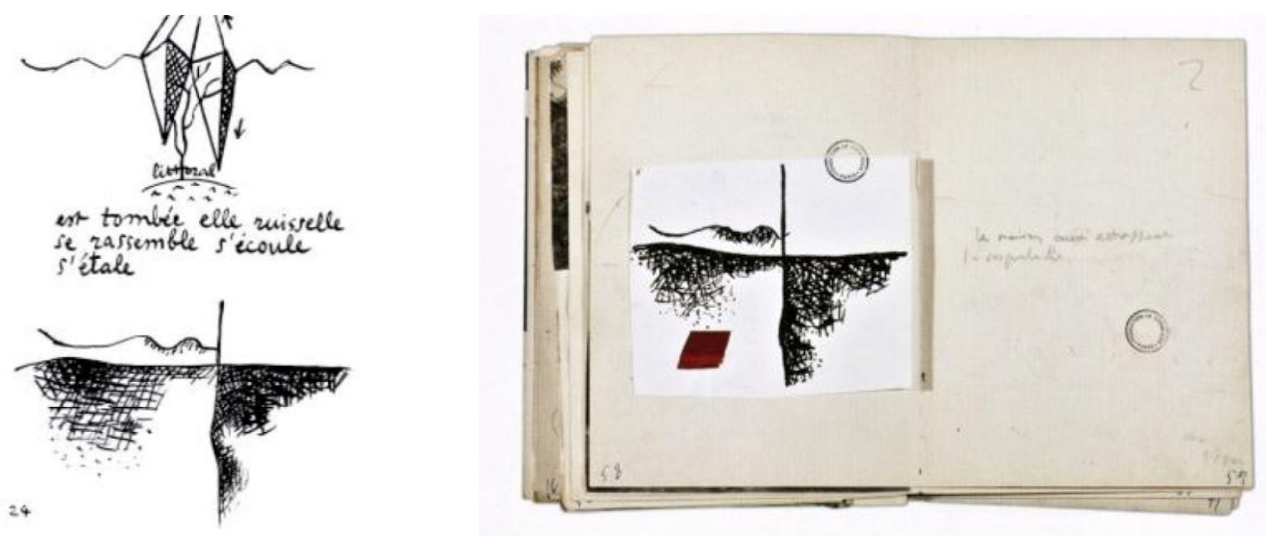

16. Imagen publicada en el Poema del Angulo Recto, p24

17. Imagen de la maquetación del libro La pequeña Casa (1954). ${ }^{39}$

No es casualidad que aparezcan hilos que vinculen las decisiones tomadas en la ciudad previamente prefigurada.

Podemos ver que en el libro hay referencias continuas sobre la concepción del espíritu de su obra, nuevamente miramos atrás y comprendemos -ese paisaje concebido desde la experiencia- aquella ciudad que tantas veces reinventó en su mente. "El ángulo recto es el útil necesario y suficiente para actuar, puesto que sirve para fijar el espacio con un rigor perfecto. "40 Esta anotación aparece publicada en 1924 justo cuando proyectaba $L a$ Pequeña Casa y cuando publicaba "Hacia una Arquitectura", 20 años antes de comenzar a escribir el Poema del Ángulo Recto (1947-1953). Le Corbusier nos dice en el mismo libro que el espíritu que anima la naturaleza es un espíritu de orden; aprendamos a saberlo. Por ello, en 1947 cuando inicia el proyecto del Poema del Angulo Recto, (mismo año que la India se independiza) nos continua hablando sobre el horizonte en la composición del paisaje del proyecto: "En el horizonte se dibuja la horizontal; se trata de dos constantes. El ángulo recto es como la integral de las fuerzas que mantienen el mundo en equilibrio. " ${ }^{\prime 1}$ El libro contiene una estructura que está organizada por medio de imágenes que representan la lucha que el lleva año tras año para poder alcanzar su

\footnotetext{
${ }^{36}$ Espacio inefable traducido en la versión castellana, sin embargo el término en su idioma original es L'espace indicible escrito en 1945 y publicado un año después en Architecture D'Ajourdui; donde exigía una autentica refundación espiritual del entorno humano bajo el signo de la armonía. CALATRAVA, J. Le Corbusier y las Síntesis de las Artes, Madrid, 2006

${ }^{37}$ Le Corbuiser, Una pequeña Casa, p.15

${ }^{38}$ Calatrava, J. Le Corbusier y la Síntesis de las Artes, Madrid, 2006

${ }^{39}$ AA.VV. Construire l'image Le Corbusier et la Photographie, París, 2012

${ }^{40}$ Le Corbusier. La ciudad del Futuro, p28

${ }^{41}$ Ibídem, p.31
} 
pensamiento y llevar a ideliazar sus proyectos. Hay un orden, hay una trama, elementos de Chandigarh de una u otra manera, allí hallamos una imagen que representa el esquema planteado por Le Corbusier en Chandigarh, porque seguramente esta idea configurada formaba parte de sus composiciones respecto al día a la noche, al lugar a los meridianos, a la naturaleza, al parecer ya es una idea que va construyéndose poco a poco en el tiempo.

No nos interesa encontrar simbolismos ni buscar asociaciones entre sí, sino más bien prestar atención a aquellas coincidencias que se vienen dando entre momentos que han sido parte de sus anotaciones en los carnets, fotografías de viaje y luego en los momentos que comenzaron a configurar Chandigarh.

La figura de la pequeña jornada establece el contacto con las 24 horas, con el sol, con la composición de la arquitectura a través del movimiento solar, determinando así el valor de un paisaje marcando el eje de coordenadas mediante una línea vertical. Una imagen más aparece en el Poema del Angulo Recto marcando los 7 momentos de reflexión, aparece el sol coronando el amanecer y quizás la espada está ahí para defender el día precursor de la luz y custodio de la naturaleza, brilla en amarillo porque refleja ese poder del luminoso sol que defiende la vida, aun cuando ya no la quiera el hombre. Esa composición se repite luego páginas más adelante haciendo un poema sobre las visiones que se tiene desde arriba cuando uno sobrevuela por las cordilleras, los Andes y los Alpes. En su viaje a Sur América llenó cuadernos con dibujos de montañas, mares, ríos serpenteantes y cielos diáfanos, todo ello recogido en el Poema, es una oda a la naturaleza, de su espíritu y de la geografía que tanto entusiasmaba.
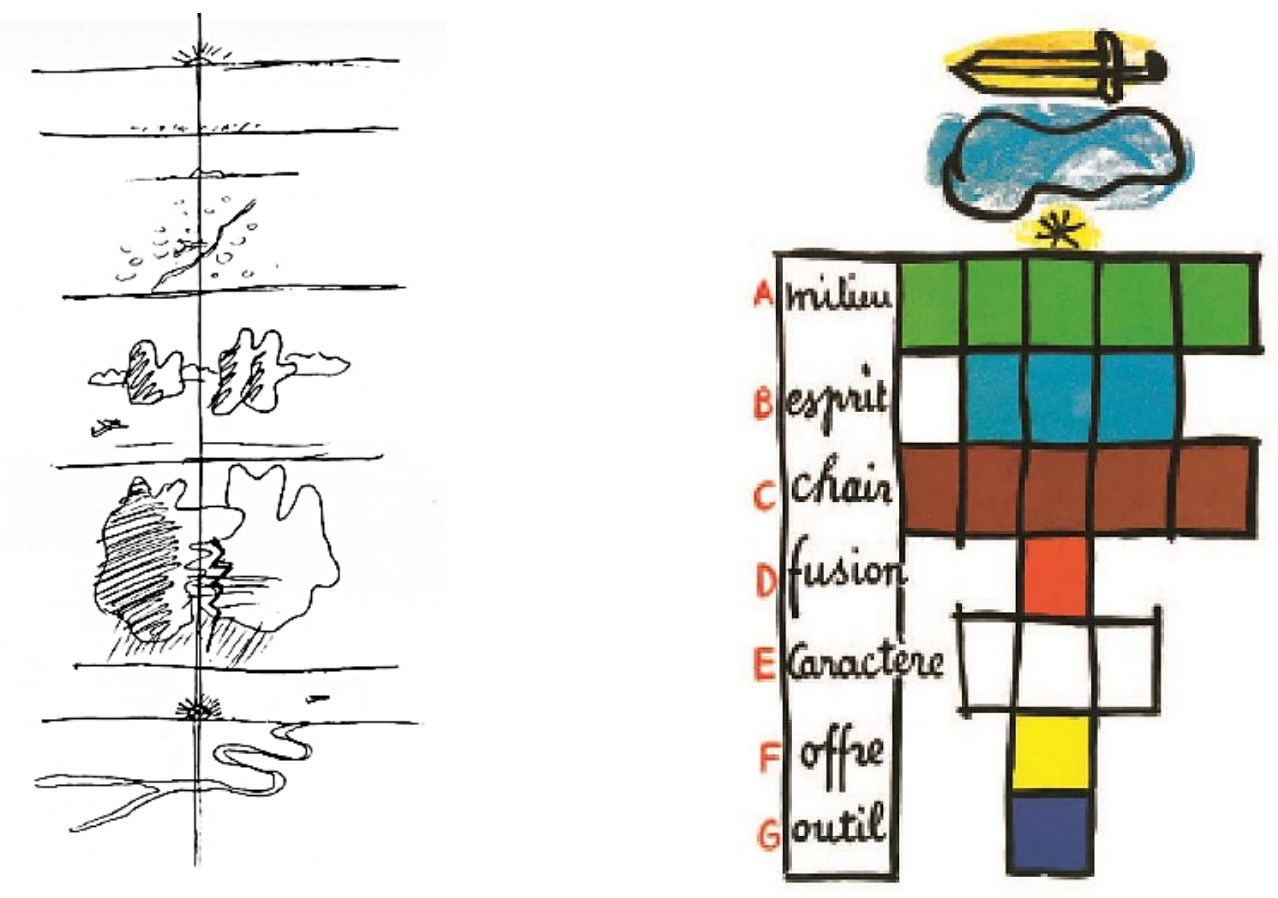

18. Pequeña meditación sobre una jornada completa ${ }^{42}$

19. Poema del Ángulo Recto, p.8

\footnotetext{
${ }^{42}$ Le Corbusier et Pierre Jeanneret, Euvre complète 1957- 1965 Vol 7_ O. Stonorov y W. Boesiger. Zürich: H. R. Grisberger \& Cie, 1937
} 
En la página 39 del Poema del Ángulo Recto aparecen dos gráficos; el superior nos recuerda las estancias sobre las terrazas en los palacios de Jaipur, madre con niño al amparo de la sombra, enmarcando el paisaje, el dibujo inferior esta girado quizás como lo concibió meridionalmente, la orientación del dibujo jerarquiza un orden y una trama que organiza trazando unas líneas como ríos que se entrelazan con la naturaleza. Al lado hemos colocado el mapa de Chandigarh que busca organizarse bajo pautas similares a las graficadas en el Poema del Angulo Recto, vemos la organización reticular. Si fue antes o después no interesa, lo que importa es que este en ese poemario que es parte de la razón que fundamenta su posición frente a la naturaleza y al hombre.

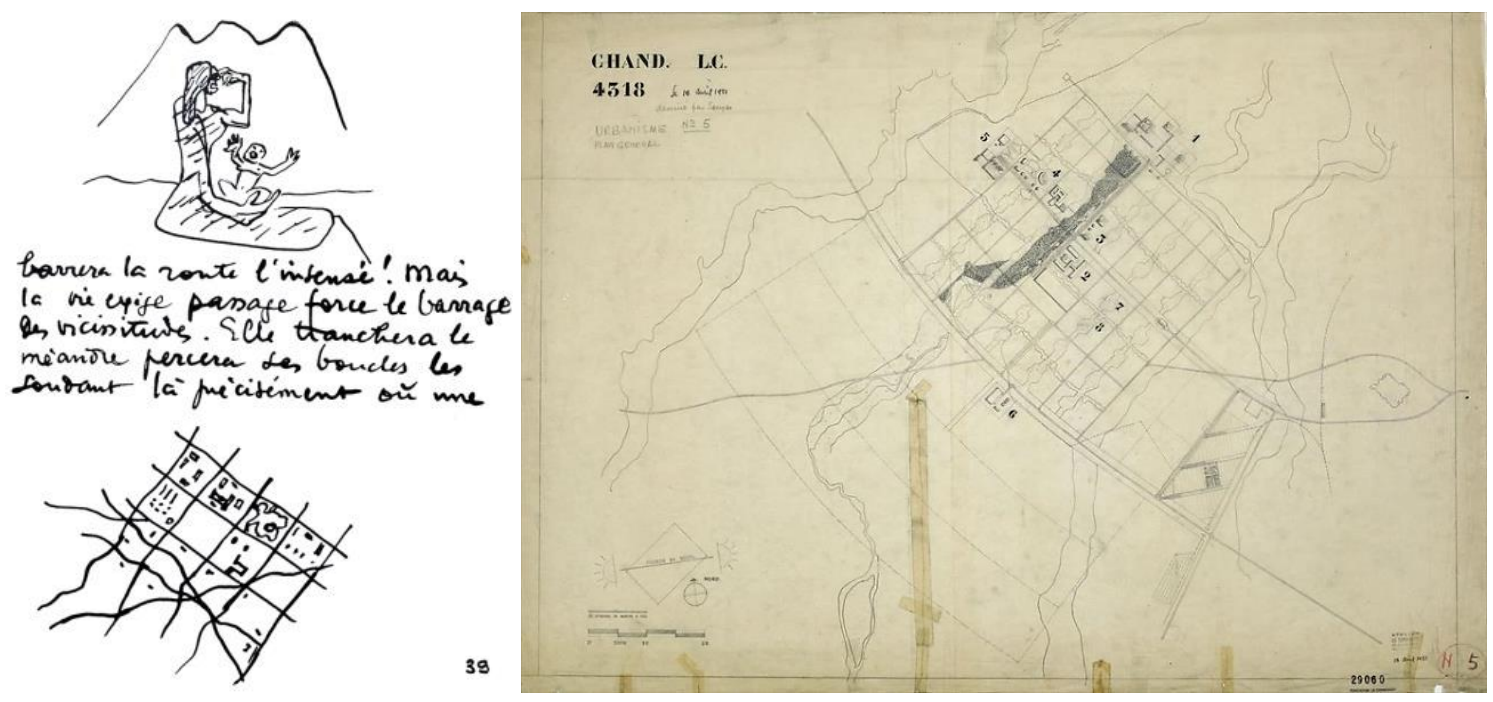

20. El Poema del Ángulo Recto, A-4 Medio, p.38

21. Chandigarh, Plan General n ${ }^{\circ}$. CHD L.C. $4318^{43}$

\section{La mano abierta, una idea de monumento}

Ahora nos toca mirar al monumento, a ver quienes observan y ser nuevamente los observados - como dice Quetglas- quizás en el Panteón de Foch, de 1929, sea la primera ocasión donde Le Corbusier se enfrenta a la idea

${ }^{43}$ Seguin, P. p.54-55 
de monumento "El monumento solemnemente, está aislado. Él también, y puede servir como lección de sensatez" 44 El monumento a la mano abierta probamente sea una lección de sensatez porque allí está tallada toda una trayectoria, representa el esfuerzo y la visión de lograr un lugar concebido con la esencia de cada una de sus partes. La mano abierta de alguna manera ya estaba construida -en su mente- cuando Le Corbusier decide colocarla en Chandigarh.

La mano abierta forma parte de ese constructo elaborado durante muchos años con ideas y dibujos de sus viajes. Aparece siempre la voluntad de entender la mano abierta como un signo o símbolo, sin embargo hay motivos para comprender que la mano abierta es una sucesión de dibujos concretos de la mano que va desde 1951-1963, también aparece un texto que pretende justificar su resolución "En un tarde, en la Rest- House en Chandigarh, estando reunidos Jaen Drew, Pierre Janeret, Maxwell Fry y Le Corbuiser, la primera tomo la palabra y dijo; Le Corbusier, usted debe de instalar en el corazón mismo del capitolio, los signos mediante los cuales ha llegado usted a expresar de un lado el urbanismo, y de otro lado su pensamiento filosófico; estos signos merecen ser conocidos, son la clave de creación de Chandigarh ${ }^{45}$ Pensamos que podría ser una razón, pero pensamos que la razón misma no es la que erigió dicho monumento.

Es sabido que Le Corbusier rechaza en todo momento que dicho se haga una interpretación y declara; "el Monumento a la mano abierta, por ejemplo del que habla Soltan, no es un signo político, una creación de político. Es una creación de arquitecto, un fruto de arquitectura. Hay en esta creación un caso específico de neutralidad humana: lo que crea depende de las leyes de la física, de la química, de la biología, de la ética, de la estética, todas juntas reunidas en una sola gavilla: una casa, una ciudad. [...]Esta mano abierta signo de paz y de reconciliación, debe erigirse en Chandigarh, este símbolo que me preocupa hace muchos años en mi subconsciente debe existir para llevar un testimonio de armonía” [...]Antes de encontrarme un día (más tarde) en las zonas celestes entre las estrellas del buen Dios, seré feliz de ver en Chandigarh, delante del Himalaya que se eleva verticalmente sobre el horizonte, esta mano abierta que marca para el pére Corbu un hecho, una etapa recorrida." 46
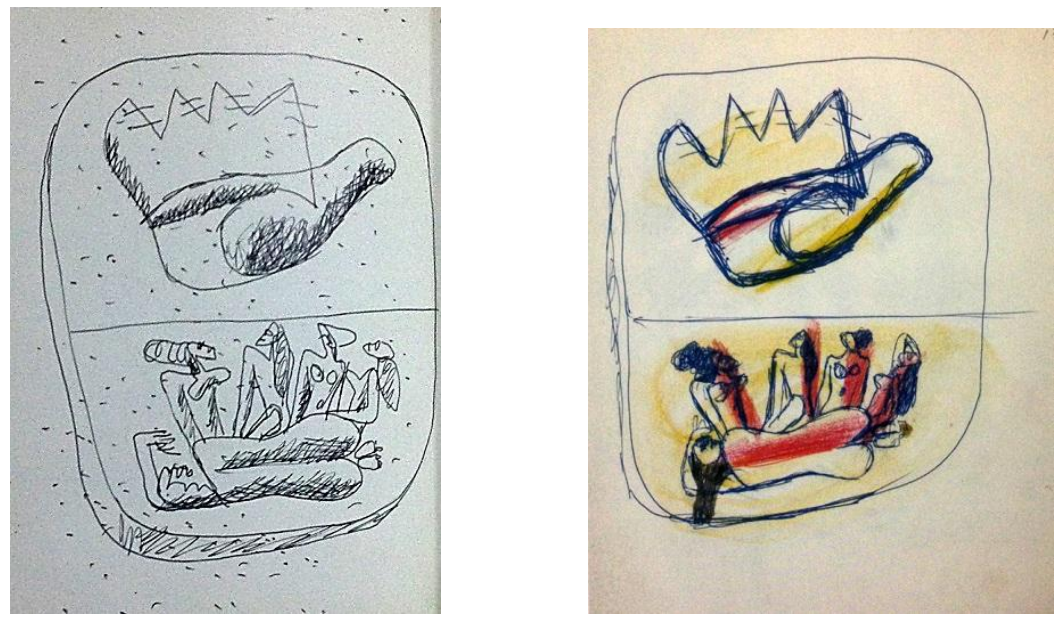

22. Dibujo de la Mano abierta en blanco y negro, $1951^{47}$

23. Dibujo de la Mano abierta en color, $1951^{48}$

\footnotetext{
${ }^{44}$ Quetglas, J. Pasado a Limpio, II, Girona, 2001

${ }^{45}$ Este comentario no tiene fechada la referencia- el lugar podría ser Chandigarh-pero podría situarse entre los años 19521954 ya que fue el tiempo que estuvieron colaborando en Punjab según los archivos del Centro Le Corbusier en Chandigarh, Le Corbusier 1910-1965, Barcelona, 2005.

${ }^{46}$ Le Corbusier, Mise au Point, Madrid, 2014

${ }^{47}$ VV.AA, Le Corbusier, Le Grand, p.455
} 

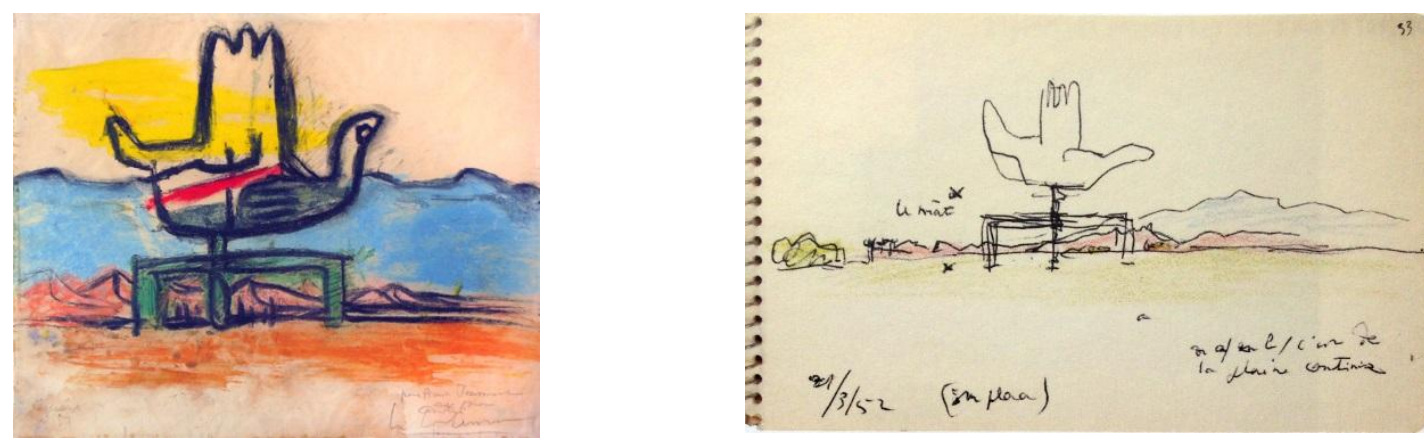

24. Dibujo de la Mano abierta insertado en el lugar dedicado a su primo "Pour Pierre Jeanneret, avec mon amitié", $1951^{49}$
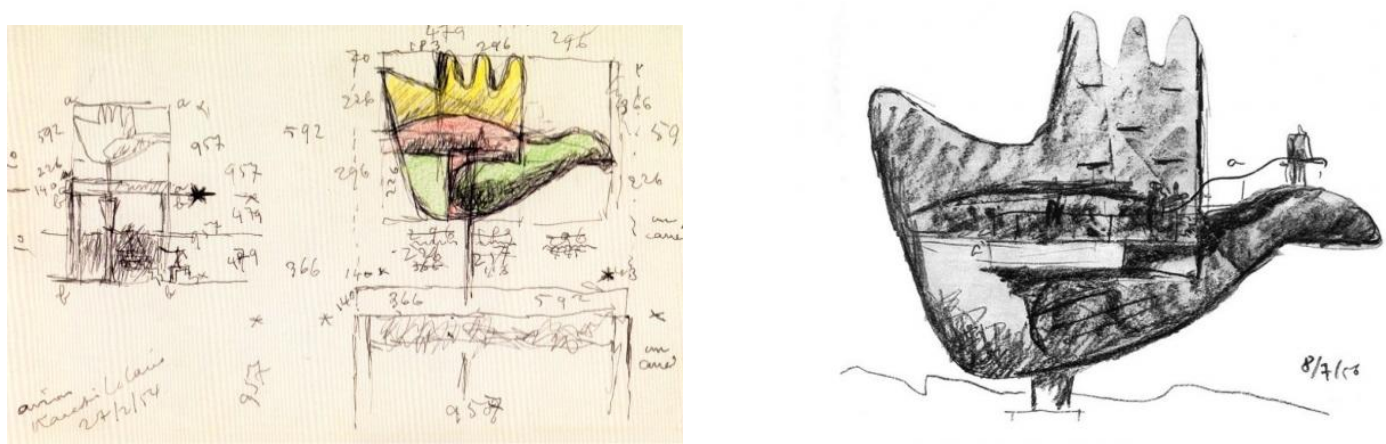

26. Dibujo de la Mano abierta detallando medidas, $1954^{51}$

27. Dibujo de la Mano abierta en blanco y negro, $1956^{52}$

Los dibujos en el tiempo van teniendo distintas representaciones o al menos "derivadas de", incluso se ha llegado a comparar con otros dibujos en donde los dedos aparecen en forma de las montañas como el dibujo del lago Leman. Lo más cercano a su concreción es el mapa elaborado en 1946 para la restructuración urbana de St. Dié podemos ver que tiene casi esa forma, me inclino a pensar que en el hecho de dibujar constantemente algo haya significado cierta pregnancia, claro, es muy reductivo pensar que puede ser solo ello, pero necesitamos armar todas las pesquisas para tener una definición más precisa. En el viaje a Bogotá (1951) aparece un dibujo que podría ser también el origen de este monumento (Fig.20, 21)

\footnotetext{
${ }^{48}$ Ibídem

${ }^{49}$ ChampetieR, M. Galerie http://www.mchampetier.com/Tecnica_mixta_firmada-Jeanneret-Le.Corbusier-14110quintaesencia.html

${ }^{50}$ Seguin, P. p.299

${ }^{51}$ VV.AA, Le Corbusier, Le Grand, p.454

${ }^{52}$ VV.AA, Le Corbusier, Le Grand, p.552
} 

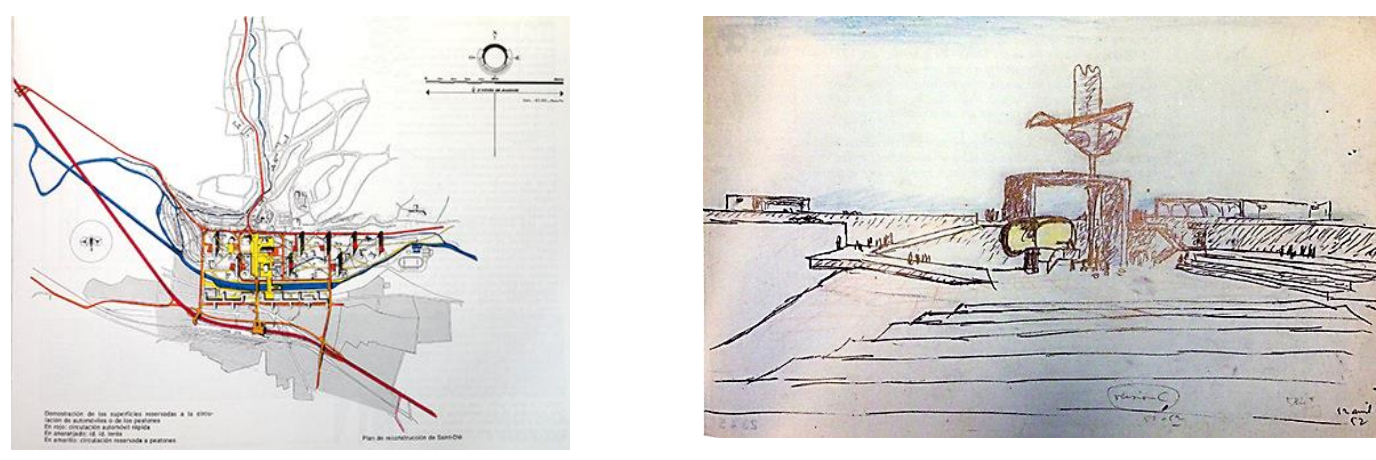

28. St Dié, $1946^{53}$

29. La Mano abierta, 1952

De alguna manera concuerdo con Frampton "en ese contexto, la mano abierta de Chandigarh, sin construir, le obsesionó hasta el último momento. Parecía pensar que no podría morir en paz mientras no fuera realizada. $Y$ es en efecto, su legado último a ese "otro" no eurocéntrico ese Tercer Mundo que le había proporcionado su única oportunidad de construir una ciudad entera, e incluso un nuevo mundo, a partir de la nada o de casi nada. " material que tenia en mente, con todo lo que haia coleccionado en todo este tiempo, observó, viajó, construyó, anotó cada detalle que vio y con todo ello ha construido la ciudad, por ello iniciaba mi presentación con esta frase; "Quizás la única ciudad que no diseño Le Corbusier fue Chandigarh, tan solo construyo sobre ella”.

Le Corbusier establece un sentimiento muy fijado a esa voluntad de su viaje instructivo que termina siempre recordándonos a Chandigarh:

$Y$ sin embargo escribo con los ojos que han visto la Acrópolis y vuelvo feliz

Oh!

Luz!

Mármoles!

\section{Monocromía!}

Frontones abolidos menos el del Partenón, contemplador del mar, masa de otro mundo, el que toma a un hombre y lo coloca por encima del mundo. ¡Acrópolis que acoge que eleva! La alegría de volver acordarme me asalta por completo, y es fortificador el sentimiento de llevarme la vista de esas cosas como una parte nueva de mi existencia, desde ahora inseparable,, 55

\footnotetext{
${ }^{53}$ AA.VV Le Corbusier 1910-1965, Barcelona, 2005

${ }^{54}$ Frampton K, Le Corbusier, Madrid, 2002

${ }^{55}$ Le Corbusier. Por las cuatro rutas, Barcelona, 1972
} 
La última versión de la mano abierta contiene todos los elementos, el hombre por sobre todo; si bien cuando se ha construido no está, Le Corbusier lo ha colocado, incluso en el plano sobre el territorio sujeta con una mano aquel hombrecito de madera que habían elaborado en el estudio. En la versión de 1956 representa al hombre por encima de la creación, en la imagen llega a través de una rampa hasta la falange del pulgar situándose por encima de lo natural reflejado delante del Himalaya, en el fotomontaje la mano intenta calcar el paisaje.
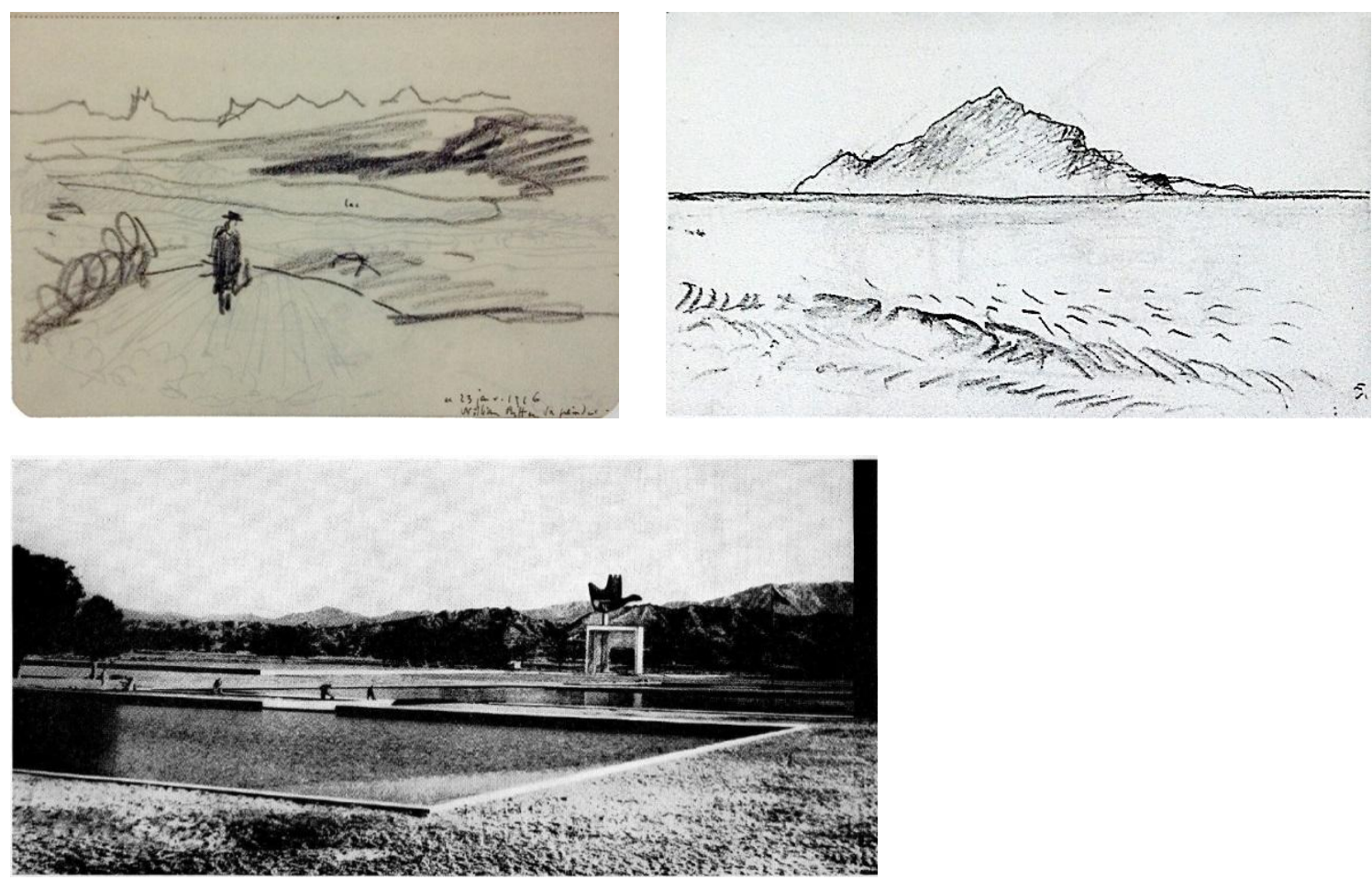

29. Willian Riter va peindre, $1916^{56}$

30. El Monte Athos. Voyage d'Orient. Carnet 3 p. $45^{57}$

31. Photo-collage showing the proposed Monument of the Open Hand before the "Pit of Contemplation" c. $1955^{58}$

El ángulo recto - de la prosa a la obra- sujeta ahora el monumento, pero éste se revela y gira sobre su propio eje para mostrar al mundo todos sus lados, redimiéndose al Himalaya, el hombre queda delante, detrás, siempre buscando lo septentrional y lo meridional de lo que está conformado el universo.

\section{Conclusiones}

Son los dibujos y anotaciones realizados en sus viajes (incluso los realizados desde el aire) los que han ido formulando ese amplio constructo - y a lo largo del tiempo han significado a nuestro parecer, más relevantes que los propios proyectos visitados- para construir otras realidades, en este caso específico, Chandigarh.

No es casualidad que cuando Le Corbusier preparaba el Mise au Point (1965) se encontraba corrigiendo los manuscritos del libro de su Viaje a Oriente escrito en 1911; en la nota figuraba "corregido 17 de julio de 1965" poco más de un mes antes de su muerte (27 agosto 1965), por ello es importante hilar La Mano abierta con su viaje a Oriente y viceversa, para comprender el viaje que hizo a lo largo de toda su vida.

\footnotetext{
${ }^{56}$ Cohen, J.L. An Atlas of Modern Landscapes. MOMA. New York, 2013

${ }^{57}$ Le Corbusier, Voyage d'Orient, Carnets, Paris, 2002

${ }^{58}$ VV.AA, Le Corbusier, Le Grand, p.461
} 
La pequeña Casa que diseño a sus padres contiene consideraciones muy específicas sobre su voluntad respecto a la arquitectura y al urbanismo. Se hizo y luego se buscó el terreno, el mismo lo explica, "Con el plano en el bolsillo, buscamos largamente el terreno. Seleccionamos varios. Pero, un día, desde lo alto de las colinas, descubrimos el verdadero terreno (1923) ${ }^{, 59}$ Es importante mencionar que en el mismo libro aparece que los planos fueron elaborados con su primo Pierre Jeanneret coincidentemente con quien colaboró en la formulación del plan para Chandigarh y a quien confió sus designios por así decirlo.

Es en la última versión y definitiva de la mano abierta (contiene las medidas) donde aparecen todos los elementos que conforman la síntesis, la recapitulación de sus pensamientos y de sus ideas en torno a toda su creación artística; alli topográficamente coloca las montañas, el angulo recto que está ligado al horizonte y al poema mismo (Medio, Espíritu, Carne, Fusión, Caracteres, Ofrenda, Útil, instrumento), también a los 5 puntos de la arquitectura que aparecen como líneas horizontales que marcan a modo de escalera el ingreso a su obra de la que siempre se asciende para ingresar.

La mano abierta es el motivo del Poema del Angulo Recto y también como confluyen esas alegrías esenciales, junto a ello se ha configurado ese ideal de urbanismo que tuvo asidero finalmente en Chandigarh. Allí la primera piedra ya estaba colocada solo faltaba un Le Corbusier para explicarla. La mano abierta es una huella del Poema sobre el cielo que pretende explicar en $360^{\circ}$ su relación con el mundo y la sobre la trayectoria del sol.

Las constantes reivindicaciones con la naturaleza dirigidas finalmente en el Poema del ángulo recto (1956) y sus demás teorizaciones desde el urbanismo terminaron por construir un paisaje previo, ese "espacio inefable " habla del primer gesto del hombre por ocupar el espacio y que rehúye casi finalmente al Cabanon en sus últimos días; momentos lleno de circunstancias y de naturalezas ya prefijadas. Cuando apareció el encargo de diseñar Chandigarh tuvo necesariamente que pensar en la porción de agua y así dio origen al lago Sukhna que era lo que le faltaba a su paisaje imaginado. De esa manera preservaría su filosofía y mantendría a salvo sus alegrías esenciales que tanto insistía. El sol, espacio y árboles concebidos como "alegrías esenciales" que explica en "Cuando las Catedrales eran Blancas, 1937" se ven reflejadas en Chandigarh.

Chandigarh ha sido concebida mediante el constructo de la razón y recorrerla es hallar horizontes que se descubren al acercarse a cada lugar, recorrer las distancias para llegar a cada edificio y manteniendo en todo momento la atención sobre esa compleja concepción de la arquitectura; allí es donde depositó todos sus propósitos por cuanto vivó.

La mano abierta contiene todas las miradas y ángulos posibles, gira, tiene dos lados posibles, el horizonte sigue recto, la mano sobre su ángulo recto seguirá buscando el horizonte, el paso de las 24 horas donde múltiples miradas que hacen al observador del paisaje un nuevo y atento ser.

\section{Referencias bibliográficas}

AA.VV. Le Corbusier y las Síntesis de las artes; El poema del ángulo recto. Madrid, 2006

AA.VV. Le Corbusier 1910-1965. Barcelona, 2005

AA.VV. Le Corbusier / Lucién Hervé Contacts. Italie, 2011

VV.AA, Le Corbuiser Le Grand, New York, 2008

\footnotetext{
${ }^{59}$ Le Corbusier, La pequeña casa, p.11

${ }^{60}$ Le Corbusier, El Modulor, p.5
} 
Baker, G. Análisis de la forma. Barcelona, 2000

Brooks, A. Le Corbusier's formative years, Charles- Edouard Jeanneret At la Chaux-des-Fonts. Chicago, 1997

Calatrava, J. Le Corbusier y la Síntesis de las Artes. Madrid, 2006

Cohen, J.L. An Atlas of Modern Landscapes. MOMA. New York, 2013

Daza, R. Tras el Viaje de Oriente. Barcelona, 2015

Huse, M. Le Corbusier. Barcelona, 1986

Le Corbusier. Aircraft. Madrid, 2003

Le Corbusier et Pierre Jeanneret, CEuvre complète Volúmenes 5, 6, 7 _ O. Stonorov y W. Boesiger. Zürich: H.

Le Corbusier. El Modulor /El Modulor 2. Madrid, 2005

Le Corbusier, Cuando las Catedrales eran Blancas. Madrid, 2007

Le Corbusier. Cómo concebir el urbanismo. Argentina, 2013

Le Corbusier. La ciudad del Futuro. Argentina ,2013

Le Corbusier. (CH.-E.Jeanneret). Vogaye d'Orient, Carnets. Milano, 2002

Le Corbusier. Una Pequeña Casa. Argentina, 2014

Morel, G. Le Corbusier. Construire la Vie Moderne. París, 2015.

Quetglas, J. Pasado a Limpio, II. Girona, 2001

Seguin, P. Le Corbusier Pierre Jeanneret (Chandigarh India). Francia, 2014

Sitte, C. La Construcción de Ciudades según principios artísticos. Barcelona, 1929

Touchaleaume, E; Moreau,G. Le Corbusier Pierre Jeanneret. L'aventure Indienne. Paris, 2010

Torres, J. Pensar la Arquitectura: Mise au point de Le Corbusier. Madrid, 2014 